8.Diu, A., F. Romagné, C. Genevée, C. Rocher, J.-M. Bruneau, A. David, F. Praz and T. Hercend. 1993. Fine specificity of monoclonal antibodies directed at human $\mathrm{T}$ cell receptor variable regions: comparison with oligonucleotide-driven amplification for evaluation of $\mathrm{V} \beta$ expression. Eur. J. Immunol. 23:1422-1429.

9.Gorski, J., M. Yassai, X. Zhu, B. Kisella, C. Keever and N. Flomenberg. 1994. Circulating $\mathrm{T}$ cell repertoire complexity in normal individuals and bone marrow recipients analyzed by CDR3 size spectratyping. J. Immunol. 152:5109-5119.

10.Gulwani-Akolkar, B., D.N. Posnett, C.H. Janson, J. Grunewald, H. Wigzell, P. Akolkar, P.K. Gregersen and J. Silver. 1991. $\mathrm{T}$ cell receptor $\mathrm{V}$-segment frequencies in peripheral blood $\mathrm{T}$ cells correlate with human leukocyte antigen type. J. Exp. Med. 174:1139-1146.

11.Gulwani-Akolkar, B., B. Shi, P.N. Akolkar, K. Ito, W.B. Bias and J. Silver. 1995. Do HLA genes play a prominent role in determining $\mathrm{T}$ cell receptor $\mathrm{V} \alpha$ segment usage in humans? J. Immunol. 154:3843-3851.

12.Hawes, G.E., L. Struyk and P.J. van den Elsen. 1993. Differential usage of T cell receptor $\mathrm{V}$ gene segments in $\mathrm{CD}^{+}$and $\mathrm{CD}^{+}$ subsets of $\mathrm{T}$ lymphocytes in monozygotic twins. J. Immunol. 150:2033-2045.

13.Kshirasagar, A.M. 1972. Distribution of correlation coefficients, p. 83-92. In Multivariate Analysis. Dekker, New York.

14.Loh, E.Y., J.F. Elliott, S. Cwirla, L.L. Lanier and M.M. Davis. 1989. Polymerase chain reaction with single sided specificity: analysis of T cell receptor $\delta$ chain. Science 243:217220.

15.Lovebridge, J.A., W.M.C. Rosenbert, T.B.L. Kirkwood and J.I. Bell. 1991. The genetic contribution of human T-cell receptor repertoire. Immunology 74:246-250.

16.Robinson, M.A. 1992. Usage of human T-cell receptor $\mathrm{V} \beta, \mathrm{J} \beta, \mathrm{C} \beta$ and $\mathrm{V} \alpha$ gene segments is not proportional to gene number. Hum. Immunol. 35:60-67.

17.Wucherpfennig, K.W., J. Newcombe, H. Li, C. Keddy, M.L. Cuzner and D.A. Hafler. 1992. T cell receptor $\mathrm{V} \alpha-\mathrm{V} \beta$ repertoire and cytokine gene expression in active multiple sclerosis lesions. J. Exp. Med. 175:993-1002.

Address correspondence to David G. Haegert, Discipline of Laboratory Medicine, Faculty of Medicine, Memorial University of Newfoundland, Health Sciences Centre, St. John's, NF, Canada, A1B 3V6.

Internet:dhaegert@morgan.ucs.mun.ca

Received 19 January 1996; accepted 2 January 1997.

Enoch S. Daniel, Veeresh G. Gadag and David G. Haegert Memorial University of Newfoundland St. John's, NF, Canada

\section{Intracellular Expression and Purification of the c-kit Receptor Kinase Domain in Pichia pastoris}

BioTechniques 23:82-86 (July 1997)

Protein-tyrosine kinases (PTKs) are key enzymes that mediate signals involved in the activation, growth and differentiation of cells in multicellular organisms. The c-kit receptor is a PTK that is critical for the growth and differentiation of several cell types including hematopoietic stem cells, mast cells, melanocytes and germ cells (6). A proper understanding of how this and other PTKs control cellular functions requires knowledge of their enzymatic regulation and their interaction with substrates. One useful approach for analyzing these properties is to express these enzymes in heterologous hosts (1). The potentially higher expression levels and ease of manipulation facilitate purification, mutagenesis and subsequent analysis.

To facilitate understanding of how the c-kit kinase is regulated, we have been expressing, purifying and analyzing the activity of the c-kit catalytic domain in the yeast organism Pichia pastoris. This host, which is easy to manipulate genetically, offers the advantages of a eukaryotic system such as appropriate protein processing and folding, with potentially very high levels of recombinant protein expression (4). However, in the course of our experiments, we encountered a problem of protein precipitation in lysates made from P. pastoris cells. We describe suitable lysis and purification conditions that eliminate this precipitation problem. In conjunction with affinity purification, this system provides a simple method for the expression and purification of intracellular proteins. Also, the lack of detectable endogenous tyrosine kinase activity in P. pastoris makes the system ideal for kinase expression with no background activity (unpublished).

pHIL-D2, a P. pastoris-specific integrating shuttle vector (Pichia Expression Kit; Invitrogen, San Diego, CA, USA) was used for transfer and intracellular expression of the c-kit catalytic domain. This vector encodes the alcohol oxidase (AOX1) promoter and 3'AOX1 DNA to promote homologous recombination, AOX1 transcriptional termination sequence, a histidinol dehydrogenase (HD)-selectable marker, ampicillin resistance and an $\mathrm{f} 1$ origin of replication. The cDNA for the cytoplasmic domain of c-kit and an N-terminal linker encoding the IBI FLAG ${ }^{\circledR}$ epitope (Scientific Imaging Systems, Eastman Kodak, Markham, ON, Canada) were ligated into a unique EcoRI restriction site located immediately $3^{\prime}$ to the AOX1 promoter. Digestion of the vector with NotI yields a linear fragment that includes the $5^{\prime}$-AOX 1 promoter, the gene of interest, transcriptional termination sequence, HD and 3'-AOX1 DNA. Linearized vector DNA was transformed into zymolyase-treated (ICN, Montreal, QC, Canada) yeast cells with a solution containing $10 \mathrm{mM}$ Tris-HCl, $\mathrm{pH} 7.5,10 \mathrm{mM} \mathrm{CaCl} 2,20$ (wt/vol) polyethylene glycol (PEG) 3350 (3).

Transformants were selected in a two-step process. First, cells were plated on histidine-deficient media to select for HD-positive transformants. Typically, we obtained $10 \mathrm{HD}$-positive colonies per microgram of linearized DNA. Colonies were then picked and streaked onto two plates, one with dextrose as a carbon source (MD) and the other using methanol as a carbon source (MM). Those that grow well on MD but not MM plates are likely to have a disrupted $A O X I$ gene, indicating transformation by homologous recombination. The frequency of $\mathrm{MD}^{+} / \mathrm{MM}^{-}$ colonies was typically $40 \%$. Approximately $25 \mathrm{MD}^{+} / \mathrm{MM}^{-}$colonies were screened for expression, and all were positive for the c-kit catalytic domain.

For recombinant protein expression, glycerol-based medium (MGY) was inoculated with cells and grown overnight in baffled flasks at $30^{\circ} \mathrm{C}$ to an optical density (OD) 600 of 1.0-2.0. Cells were harvested by centrifugation $(4000 \times g)$ and the pellet resuspended in methanol-based medium for induction of expression under the same conditions. Recombinant protein expression was followed over a period of 6 days by Western blotting with the anti-FLAG antibody M2.

Optimal expression was observed 4 days after induction. The effect of dif- 
ferent concentrations of methanol on protein expression was also determined. Twofold higher recombinant protein expression was observed if cells were induced with $4 \%$ methanol instead of the recommended $0.5 \%$ (Pichia Expression Kit). However, the higher methanol content appeared to inhibit the expression of a similarly expressed activating mutant c-kit catalytic domain. Therefore, optimal methanol content of the inducing medium is likely to vary from strain to strain and will thus require empirical determination.

Lysis of yeast cells was performed by vortex mixing with an equal volume of glass beads. The lysis buffer included $50 \mathrm{mM} \mathrm{NaPO}_{4}$ (pH 7.4), $1 \mathrm{mM}$ phenylmethylsulfonyl fluoride (PMSF), $1 \mathrm{mM}$ EDTA and 5\% glycerol. Lysates were mixed with an equal volume of prewashed glass beads (450-600- $\mu \mathrm{m}$ diameter; Sigma Chemical, Mississauga, ON, Canada) and vortex mixed in 30-s intervals alternating with $30 \mathrm{~s}$ on ice for a total of $8 \mathrm{~min}$. Following lysis, membrane and debris were removed by centrifugation $(13800 \times g)$.

The phosphate lysis buffer was necessary for lysis but unsuitable for purification, because heavy precipitation occurred after addition of the antiFLAG agarose beads. This precipitation was not due to expression of the c-kit catalytic domain because it also occurred in lysates from nontransformed P. pastoris cells. Nor was it specific for beads with anti-FLAG antibodies attached, because precipitation also occurred with unconjugated beads. Therefore, it appeared that the beads were acting as a nucleating factor for the precipitation of $P$. pastoris proteins, resulting in co-precipitation and loss of the recombinant enzyme.

We therefore performed a systematic investigation of the different buffer components to find conditions under which this precipitation could be prevented. Lysates were dialyzed overnight into solutions with different buffering components, salt concentration and $\mathrm{pH}$. Dithiothreitol (DTT) was included in the first dialysis to prevent oxidation of the kinase domain. The next day, dialysis was continued in the same buffer without $1 \mathrm{mM}$ DTT to reduce the possibility of antibody leaching from the anti-FLAG beads. Deter-

Table 1. Dialysis Buffer Composition and Precipitation of Lysate Protein

\begin{tabular}{|lllcl|}
\hline Buffer & $\begin{array}{c}\mathbf{N a C l} \\
(\mathbf{m M})\end{array}$ & $\mathbf{p H}$ & $\begin{array}{c}\text { Triton X- } \\
\mathbf{1 0 0}(\%)\end{array}$ & Precipitation \\
\hline Phosphate & 150 & 7.4 & 0 & Y (dialysis) \\
Tris-HCl & 150 & 7.4 & 0 & Y (dialysis) \\
HEPES & 150 & 7.4 & 0 & Y (dialysis) \\
HEPES & 150 & 7.4 & 2.5 & Y (dialysis) \\
HEPES & 0 & 8.0 & 0 & Y (lysis) \\
HEPES & 150 & 8.0 & 0 & Y (lysis) \\
Tris-HCl & 50 & 6.0 & 0 & Y (lysis) \\
Tris-HCl & 0 & 6.0 & 0 & N (lysis) \\
HEPES & 150 & 7.4 & 5 & N (beads) \\
HEPES & 150 & 8.3 & 5 & N (beads) \\
HEPES & 150 & 8.3 & 2 & N (beads) \\
HEPES & 150 & 8.3 & 1 & Y (beads) \\
P. pastoris lysates were dialyzed into solutions with the listed buffering agent, pH \\
and salt concentration. All buffers contained 1 mM DTT, 1 mM EDTA and 10\% \\
glycerol. Detergent was added before centrifugation at 250 000 $\times$ g. Precipitation \\
was noted after lysis, during dialysis or after addition of agarose beads.
\end{tabular}

gent, when included, was added before the lysate was centrifuged at $250000 \times$ $g$ for $40 \mathrm{~min}$ at $4^{\circ} \mathrm{C}$.

The buffer compositions that were analyzed for their ability to cause or prevent precipitation of proteins are listed in Table 1. The buffers also contained $1 \mathrm{mM}$ EDTA and 10\% glycerol. It was determined that $\mathrm{pH}$ and salt concentration were critical in affecting flocculate formation after lysis, when the first dialysis was initiated or when beads were added to the lysate. Buffers containing $10 \mathrm{mM}$ HEPES (pH 8.0), with or without $\mathrm{NaCl}$, induced precipitation. Precipitation still occurred when the $\mathrm{pH}$ of the buffer was lowered to slight acidity ( $\mathrm{pH} 6.0)$ and $\mathrm{NaCl}$ was added, but it was prevented in the absence of salt at pH 6.0. However, affinity purification required $\mathrm{pH}$ values higher than neutral; therefore, only $\mathrm{pH}$ levels of 8.0 or higher were subsequently considered. When lysate at $\mathrm{pH} 8.3$ was added to the column, precipitation was still observed, although the amount appeared to decrease. We found that the precipitation caused by the addition of beads to lysates at neutral $\mathrm{pH}$ could be prevented when high levels of detergent were added. Triton ${ }^{\circledR}$ X-100 (5\%) eliminated flocculate formation, but a lower amount of $2 \%$ Triton X-100 was insuf- ficient in preventing precipitation at $\mathrm{pH}$ 7.4. We therefore combined the high $\mathrm{pH}$ condition with detergents and found that the addition of $2 \%$ or $5 \%$ Triton X100 was sufficient to prevent precipita-

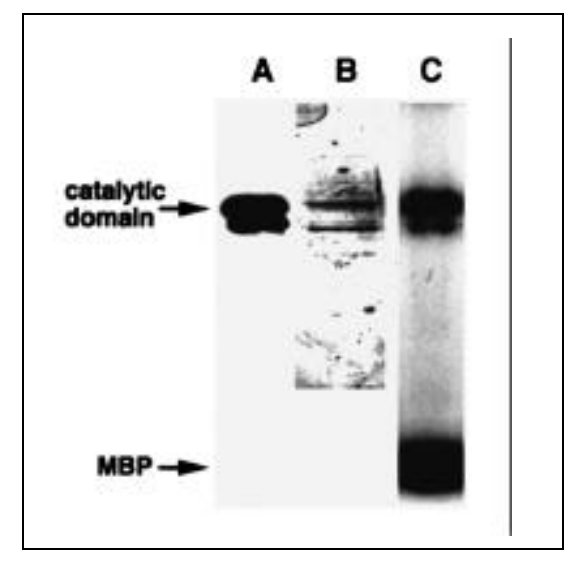

Figure 1. Analysis of purified protein for specificity, purity and activity. Purified protein fractions were separated by sodium dodecyl sulfate polyacrylamide gel electrophoresis (SDS-PAGE) and (A) transferred to nitrocellulose and blotted with anti-FLAG M2 or (B) silver-stained to check for purity. (C) A kinase reaction was carried out with the purified kinase in the presence of $\mathrm{MnCl}_{2}, \mathrm{MBP}$ and $\left[{ }^{32} \mathrm{P}\right] \gamma \mathrm{ATP}$ for $10 \mathrm{~min}$ at $30^{\circ} \mathrm{C}$. Reaction mixtures were boiled and separated by SDS-PAGE. The gel was treated with $1 N \mathrm{KOH}$ before being fixed, dried and visualized by autoradiography. No reactivity with anti-FLAG antibodies has been observed in untransformed $P$. pastoris lysates analyzed by Western blot. 
tion at $\mathrm{pH} 8.3$. The combination of $2 \%$ Triton X-100 and $\mathrm{pH} 8.3$ was therefore used for affinity purification.

Affinity purification of the soluble kinase was carried out as follows. The lysate was filtered through a $0.2-\mu \mathrm{m}$ filter and then nutated with anti-FLAG M2 beads (prewashed with $0.1 \mathrm{M}$ glycine $[\mathrm{pH} 3.0]$ and dialysis buffer $[\mathrm{pH}$ 8.3]) for $1 \mathrm{~h}$ at room temperature. The flow-through was collected, and the beads were washed with a minimum of 10-20 column volumes of dialysis buffer. Elution of the kinase was carried out by adding aliquots of $0.1 \mathrm{M}$ glycine $(\mathrm{pH}$ 3.0). The fractions were neutralized by adding $1 \mathrm{M}$ Tris- $\mathrm{HCl}(\mathrm{pH} 8.0)$. Fractions were pooled and dialyzed overnight in dialysis buffer and $1 \mathrm{mM}$ DTT before being stored in aliquots at $-80^{\circ} \mathrm{C}$. Analysis of starting lysate, flowthrough and eluate by Western blot and silver stain show that the affinity purification is effective in isolating the cat- alytic domain in relatively pure form. We estimate that this single-step procedure results in a 560-fold purification with a yield of $36 \%$. Our particular $P$. pastoris strain generates approximately $100-200 \mu \mathrm{g} / \mathrm{L}$ of purified recombinant kinase. This level of production is sufficient for enzyme and other biochemical studies. Although this is lower than other expression systems, this level could potentially be increased by identifying strains with multiple copies of inserted vector (2).

In addition to the 50-kDa band, other bands of lower molecular weight are observed following affinity purification. These are likely to be degradation products due to proteolysis of the kinase that occurred during the purification step. The protease inhibitors PMSF, EDTA, leupeptin and aprotinin were ineffective in preventing this proteolysis. However, since this degradation only occurs during the affinity purification step, it is possible that it may be prevented by altering the conditions of the elution procedure.

Although unphosphorylated before purification (not shown), as shown in Figure 1, the purified kinase is fully capable of autophosphorylation and phosphorylation of an exogenous substrate, myelin basic protein (MBP). The specific activity of the protein was estimated to be $0.12 \mathrm{pmol} / \mathrm{min} / \mu \mathrm{g}$ using filterbinding assays and MBP as a substrate (unpublished). Treatment of the purified protein with glycine elution buffer followed by neutralization as in the purification procedure had a minimal effect on activity of the kinase, indicating that this elution procedure probably does not have an adverse effect on the kinase.

Previous experiments with $P$. pastoris have shown that this organism can be a very effective host for recombinant protein expression, particularly for 
secreted proteins (9). We have shown that $P$. pastoris can also be effective for intracellular expression of a PTK. Our experiments defined the appropriate combination of salt, $\mathrm{pH}$ and detergent required to prevent $P$. pastoris protein precipitation without compromising subsequent affinity purification steps.

Commonly, hosts such as E. coli or insect cells have been used for recombinant expression of PTKs $(5,7,8,10)$. We found, however, that the c-kit catalytic domain was primarily insoluble when expressed in bacteria (unpublished), complicating purification and subsequent analysis. Although $\mathrm{Sf} 9$ insect cells, in conjunction with baculovirus-based vectors, have been very useful as hosts for PTK expression, the existence of endogenous tyrosine kinase and phosphatase activity potentially limits the usefulness of these cells for this application. In conclusion, our results show that $P$. pastoris is a very convenient and useful host for expression of recombinant intracellular proteins, particularly PTKs.

\section{REFERENCES}

1.Buckholz, R.G. and M.A. Gleeson. 1991 Yeast systems for the commercial production of heterologous proteins. Bio/Technology 9:1067-1072.

2.Clare, J.J., F.B. Rayment, S.P. Ballantine, K. Sreekrishna and M.A. Romanos. 1991. High-level expression of tetanus toxin fragment $\mathrm{C}$ in Pichia pastoris strains containing multiple tandem integrations of the gene. Bio/Technology 9:455-60.

3.Cregg, J.M., K.J. Barringer, A.Y. Hessler and K.R. Madden. 1985. Pichia pastoris as a host system for transformations. Mol. Cell. Biol. 5:3376-3385.

4.Cregg, J.M., T.S. Vedvick and W.C. Raschke. 1993. Recent advances in the expression of foreign genes in Pichia pastoris. Bio/Technology 11:905-910.

5.Ellis, L., A. Levitan, M.H. Cobb and P. Ramos. 1988. Efficient expression in insect cells of a soluble, active human insulin receptor protein-tyrosine kinase domain by use of a baculovirus vector. J. Virol. 62:1634-1639.

6.Galli, M.C., P.J. Giardina, A.R. Migliaccio and G. Migliaccio. 1993. The biology of stem cell factor, a new hematopoietic growth factor involved in stem cell regulation. Int. J. Clin. Lab. Res. 23:70-77.

7.Garcia, P., S.E. Shoelson, S.T. George, D.A. Hinds, A.R. Goldberg and W.T. Miller. 1993. Phosphorylation of synthetic peptides containing Tyr-Met-X-Met motifs by nonreceptor tyrosine kinases in vitro. J. Biol. Chem. 268:25146-25151.

8.McGlynn, E., M. Becker, H. Mett, S.
Reutener, R. Cozens and N.B. Lydon. 1992. Large-scale purification and characterization of a recombinant epidermal growth-factor receptor protein-tyrosine kinase. Eur. J. Biochem. 207:265-275.

9.Ratner, M. 1989. Protein expression in yeast. Bio/Technology 7:1129-1133.

10.Watts, J.D., G.M. Wilson, E. Ettehadieh, I. Clark-Lewis, C. Kubanek, C.R. Atell, J.D. Marth and R. Aebersold. 1992. Purification and initial characterization of the lymphocytespecific protein-tyrosyl kinase p56 lck from a baculovirus expression system. J. Biol. Chem. 267:901-907.

This work was supported by a grant to S.A.B. from the National Cancer Institute of Canada. FLAG and anti-FLAG are trademarks of Immunology Ventures. Address correspondence to Stuart A. Berger, Wellesley Hospital Research Institute, 160 Wellesley St. E., Toronto, Ontario, ON, Canada. Internet:berger@whri.on.ca

Received 4 September 1996; accepted 18 December 1996.

\section{Lily P.Y. Lam and Stuart A. Berger \\ Wellesley Hospital Research \\ Institute and \\ University of Toronto \\ Toronto, ON, Canada}

\section{Generation of a Moveable $\operatorname{Poly}(\mathrm{A})^{+}$Cassette}

BioTechniques 23:86-88 (July 1997)

It has become clear that sequences in the untranslated region of mRNAs exert profound effects on the stability, translatability and subcellular localization of transcripts $(1,3)$. In particular, significant attention has been focused on the poly $(\mathrm{A})^{+}$tail. In vivo, the length of the poly(A) ${ }^{+}$tail is often in flux and can influence the stability of mRNAs (4). During cDNA library construction, the poly $(\mathrm{A})^{+}$tail is often truncated or even lost, potentially altering the behavior of subsequently generated transcripts. For direct studies of the role of the poly $(\mathrm{A})^{+}$tail, it is desirable to have a defined number of adenine residues on each transcript under investigation to remove potential artifacts.

We report a method for generating cassettes of poly $(\mathrm{A} / \mathrm{T})$ residues that can be readily transferred between vectors for the generation of in vitro-transcribed mRNAs with poly(A) ${ }^{+}$tails of defined lengths. This vector differs from other poly $(\mathrm{A})^{+}$vectors [such as the pSP64 plasmids (2)] in two respects: $(i)$ the $\mathrm{A} / \mathrm{T}$ tracts are generated by polymerization rather than resulting from reverse transcription cDNA cloning, and (ii) the cassette can be moved into other vectors already containing the gene of interest.

A modified pBluescript ${ }^{\circledR} \mathrm{KS}$ vector (Stratagene, La Jolla, CA, USA) was used that contains an altered polylinker with the following restriction sites: BamHI/BglII/BamHI. (Vectors with inverted polylinker sites, such as M13mp7/pUC7, can also be used.) The pBluescript was linearized with $B g l I I$ (all restriction enzymes from Promega, Madison, WI, USA) (Figure 1), and the ends were filled in using Klenow DNA Polymerase (Promega) according to the manufacturer's recommendations. The DNA was precipitated and resuspended at $1 \mu \mathrm{g} / \mu \mathrm{L}$ in water. The linear, bluntended vector $(2 \mu \mathrm{g})$ was incubated with $500 \mu \mathrm{M}$ dATP and terminal transferase (30 U; Promega) in a final volume of 15 $\mu \mathrm{L}$ using the buffer provided. After a 60-min incubation at $37^{\circ} \mathrm{C}$, the DNA was precipitated and the washed pellet resuspended in $10 \mu \mathrm{L} \mathrm{ddH_{2 }} \mathrm{O}$. To determine if the reaction was successful, an aliquot of the tailed DNA was digested with $P v u I I$ and size-fractionated in a $1.5 \%$ agarose gel. The addition of poly(A) ${ }^{+}$tails resulted in a smear larger than the approximately 400-bp size of the untailed fragment. The tailing reaction was repeated using a second aliquot of the linear, blunt-ended pBluescript vector with $125 \mu \mathrm{m}$ dTTP.

The two tailed vectors were then digested with ScaI, which cleaves within the ampicillin-resistance gene and produces two fragments of approximately 1 and $2 \mathrm{~kb}$. After fractionation in a $1 \%$ Low Melting Point Agarose Gel (Life Technologies, Gaithersburg, MD, USA), the larger fragment with the adenine residues and the smaller fragment 